\title{
AIRLINE FARES: A COMPARISON BETWEEN SPANISH AND FRENCH TRAVEL AGENCIES
}

José-Luis Alfaro Navarro ${ }^{1}$

University of Castilla-La Mancha

María-Encarnación Andrés Martínez²

University of Castilla-La Mancha

Jean-François Trinquecoste ${ }^{3}$

Université Bordeaux

\section{ABSTRACT}

The existence of different types of intermediaries - e-tailers, traditional or offline retailers and multichannel retailers - engaged in the sale of airline tickets has enabled consumers to find different prices if they spend time searching for information. This has prompted internet marketing research to increasingly focus on the issue of pricing, analyzing the differences between these retailers with respects to price levels, price dispersion, pricing strategies, etc. Moreover, there are also studies examining the effects of culture on prices. However, there is no literature on the effects of the culture from the supplier point of view. This paper attempts to fill in the gap by studying whether the geographical locations of the travel agencies affect airline ticket prices. In particular, the study compares the price behavior of French and Spanish intermediaries operating exclusively online and those operating simultaneously in travel agencies and on the internet (offline and online). To this end, we consider three routes that connect Madrid, Paris and New York, with data starting four months prior to the departure date (December 16, 2013). The results show several differences in the price levels and price dispersion between intermediaries in relation to the type of retailer and their geographical locations.

Keywords: Price, e-tailers, multichannel retailers, location.

\footnotetext{
1 José-Luis Alfaro Navarro, Facultad de Ciencias Económicas y Empresariales de Albacete. Plaza de la Universidad, 1, 02071, Albacete (España). Phone: +34902204100. joseluis.alfaro@uclm.es

2 María-Encarnación Andrés Martínez, Facultad de Ciencias Económicas y Empresariales de Albacete. Plaza de la Universidad, 1, 02071, Albacete (España). Phone: +34902204100. encarnacion.andres@uclm.es

3 Jean-François Trinquecoste , Université Bordeaux 4. Avenue Léon Duguit 33608 Pessac cedex, Bordeaux (France). Phone: +33 5568485 86. jean-francois.trinquecoste@u-bordeaux4.fr
} 


\section{INTRODUCTION}

The internet has revolutionized distribution channels, affecting both business models and consumer purchasing behavior. The internet provides more detailed and immediate information about consumer decision-making behavior (e.g. products searched, products bought, pages visited, and so on). At the same time, the nature of the environment and information management tools provide a more flexible and easier way to change prices more regularly (Huang et al., 2005).

In order to analyze price behavior, many papers consider the price level or price dispersion with respect to different types of retailers. This study focuses on both price level and price dispersion with respect to e-tailers and multichannel retailers, more specifically, in the case of airline fares, as an increasingly large proportion of the air tickets are sold online. We must take into account that the $72 \%$ of the European Union population used internet at least once in 2013 and $47 \%$ of the population aged between 16 and 74 years old purchased something on internet at least once in the last year (Digital Agenda for Europe Scoreboard 2014). Hotel and travel booking account for 54\% of the goods and services sold on internet to personal consumers in 2014.

Moreover, the growth of internet as a sales channel has led to a process of globalization in terms of the products marketed through this channel. Thus, customers from different countries and geographical locations can simultaneously access the internet to purchase airline tickets. As a result, research has been developed that studies how culture influences the management and purchase of airline tickets via this channel. In this regard, we have studied retailers from two countries, France and Spain, in order to analyze the effect of the retailers' geographical location on price behavior.

Although many studies that analyze the online purchase channels, most of them focus on the effect of the demand characteristics and there are few studies that consider the behavior taking into account the supplier characteristics. To this end, we analyze price behavior taking into account price variability and price level in order to determine if the retailer type and geographical location significantly affect these prices. Specifically, we have studied Spanish and French travel agencies that also have websites to sell their products, as well as one virtual travel agency that operates in the Spanish and French markets using different domains (.es and .fr, respectively). Thus, in Section 2 we carry out a literature review in order to establish the state of the research on the topic considered in this paper. In Section 3 we explain the procedure used to obtain the information and in Section 4 the main results obtained. Finally, Section 5 describes the main conclusions and future research lines arising from the main limitations of this paper. 


\section{LITERATURE REVIEW}

Internet allows consumers to have more information about products and prices thus are able to make better choices. One of the sectors most affected by the emergence of internet as sales channel is the airline industry considering the price as a key element in the election of the sale channel. In this sector, as in other, internet has led to the emergence of three types of retailers: pure-play internet e-tailers; traditional or offline retailers; and multichannel retailers (Zettelmeyer, 2000).

This situation has led several authors to study the differences in price level and price dispersion between online and offline retailers, although there is some disagreement in the results. Thus, Bailey (1998), Erevelles et al. (2001), Clay et al. (2002) and Lee and Gosain (2002) studied different kinds of products and concluded that price dispersion is higher on the internet, while the results of Morton et al. (2001) and Brown and Goolsbee (2002) attested to a lower dispersion on the internet. Moreover, the results of other papers show different behavior depending on the dispersion measurement or other characteristics. For example, Brynjolfsson and Smith (2000) concluded that when they used market-share weighting the price dispersion is lower on the internet and without this weighting the price dispersion is higher on the internet. Ancarani and Shankar (2004) revealed similar findings, whereby in terms of price range the results show higher dispersion online, but the opposite is true in terms of price standard deviation. Scholten and Smith (2002), on the other hand, concluded that the dispersion is the same in both channels. Andrés et al. (2014) showed that in the case of airline tickets, average prices are lower on Internet than in other sales channels.

In the literature on airline pricing, there are many papers analyzing the price level (Morton et al., 2001; Ancarani and Shankar, 2004; Stylianou et al., 2005; Zettelmeyer et al., 2006; Huang and Swaminathan, 2009; Gaggero and Piga, 2010; Alfaro et al., 2015); price evolution (Friesen, 2005; Alegre and Sard, 2008; Gillen and Mantin, 2009; Clark and Vincent, 2012); or price dispersion (Kannan and Kopalle, 2001; Clemons et al., 2002; Kung et al., 2002, Huang et al., 2005; Bakos et al., 2005; Stylianou et al., 2005; Alderighi, 2010; Gaggero and Piga, 2011; Obermeyer et al., 2013; Hernandez and Wiggins, 2014) in relation to different kinds of intermediaries.

Furthermore, there is growing consensus in the literature related to the importance of the role of cultural differences in consumer behavior. In this sense, Hofstede $(1980,21)$ defined culture as: "the collective programming of the mind which distinguishes members of one group or category of people from another". In addition, he considered five cultural dimensions: power distance, individualism, masculinity, uncertainty avoidance and long-term orientation. There are basically two 
lines of analysis regarding the effect of culture on customers: one studies the online travel planning behavior and the other considers the role of cultural differences in individuals' use of computers, internet use, online search behaviors and perceived risk of using the internet to purchase goods and services. In terms of the former, the papers of McLellan and Fousher (1983), Richardson and Crompton (1988), Luk et al. (1994), Pizam and Sussmann (1995), Pizam and Jeong (1996), Huang et al. (1996), Armstrong et al. (1997), Sussmann and Rashcovsky (1997), Kozak and Nield (1998), Kozak (2001), Yoon (2009), Ruiz et al. (2013) and Jordan et al. (2013) stand out. The general conclusion of these papers is that culture has a clear influence on consumer behavior, with all papers revealing a significant difference in consumer behavior based on nationality. With respect to the other line of research, the papers of Jarvenpaa et al. (1999), Chen and Gursoy (2000), Park and Jun (2003), Gursoy and Umbreit (2004) and Li and Kirkup (2007) concluded that culture moderates the relationship between the individual and their use of the internet.

On the other hand, Clay and Tay (2001) analyzed the online price dispersion of textbooks in a cross-country market. They concluded that there is substantial price dispersion across the countries studied, specifically, USA, Canada, UK and Germany. However, many studies are limited to English speaking countries ( $\mathrm{Li}, 2014$ ) and others are focused on comparing disparate cultures such as Asian versus Western cultures, with scant research into differences between European cultures (Ruiz et al., 2013). Moreover, most papers consider the customer's point of view but do not examine the influence of culture on the prices offered by different retailers.

Thus, this paper analyzes the effect of cultural differences on airline ticket prices, contributing to the literature in two ways: First, we have taken a supply side perspective by analyzing the effect of travel agency geographical location on the price level and dispersion established by the retailer. Second, we have studied two European cultures, specifically those of Spain and France. Although, a priori, it might seem that Spanish and French cultures are too similar for comparison, the results do not support this. Finally, we have included two kinds of retailer in our study: travel agencies selling online as well as in a physical location (multichannel travel agency); and online travel agencies that have no physical premises. Unfortunately we have no information about purely offline travel agencies because it is more difficult to secure their collaboration, particularly when using two geographical locations. 


\section{DATA}

In this paper we have examined the price of several flights through web pages devoted to booking and purchasing tickets. In order to include a sufficient number of flights and an in-demand route, we chose three routes: from Madrid to Paris; Madrid to New York; and Paris to New York, without stipulating a specific airport in the case of the latter destination. These routes consist of flights between the two capitals cities of the countries analyzed in this paper - France and Spain - and between the capital cities of these two countries and the high-demand destination of New York.

Firstly, we selected the companies that offer the specific flights analyzed in this paper and chose seven flights for each route, operated by different companies. For the Madrid-Paris route, we selected only direct flights operated by Air France (two flights at two different times), Iberia (two flights at two different times), Vueling and Easyjet (two flights at two different times). For the Madrid-New York route we chose direct flights with British Airways, Iberia, Finnair and American Airlines, as well as others that offer flights with a stopover, such as Aer Lingus, Turkish Airlines and Swiss. For the last route, we used direct flights operated by Iberia, Finnair, Air France and Luthansa, as well as flights with a stopover operated by Aer Lingus, Lot Polish and Swiss.

In order to find the price of the different flights, we used two types of intermediaries: those that only operate on the internet and those that operate in both traditional and virtual channels. We used only one online travel agency, lastminute, as we required an online travel agency that sells flights in different countries using different domains. Thus, lastminute offers their products in France on the www.lastminute.fr website, while in Spain the website is www.lastminute.es. In terms of travel agencies that use physical premises as well as a website to sell their products, we included the Spanish travel agencies Barcelo viajes, Nautalia and El Corte Inglés, while the French travel agencies included were Havas voyages, Look voyages and Promovacances.

The time period studied included flights departing on December 16, 2013 and returning five days later on December 21, 2013, in order to avoid peak holiday times and to obtain a representative sample of the off-peak season. The timeframe for the airfares in our database ranges from August 26 to two days before departure, because Nautalia, El Corte Inglés, Havas voyages and Look voyages do not sell flights any closer to the departure. Flight prices were monitored daily.

Finally, in the data analysis, for each kind of route and travel agency, we used the average price available each day among the prices offered by the different companies. However, in order to limit the possible options we have considered only flights with a maximum of one stopover for the specific route. The data analysis has been developed so as to study each route individually; analyzing all routes simultaneously would not have been logical. Accordingly, the Madrid-Paris route 
is referred to as route 1 , the Madrid-New York route as route 2 and the Paris-New York route as route 3 . The main results obtained appear in the following section.

\section{RESULTS}

The data is analyzed in terms of price level and price dispersion. To analyze the price level we used the average price available each day and with this information we developed analyses of variance (ANOVA). We used the coefficient of variation to measure price dispersion as this is the best way to make comparisons.

To analyze the price average we have developed several analyses of variance (ANOVAs) in order to evaluate the differences in the average price with regards to the factors considered. In this case, we have examined two factors, each with two categories; the first factor is the country where the travel agency markets their product, that is, the geographical location. In this respect, we included Spanish and French travel agencies although the data were obtained via the internet. In terms of the online travel agencies we have differentiated based on their web domain. The other factor is the channel through which the products are marketed. In this regard, we distinguished between agencies with physical premises as well as online services, and those that only sell online, that is, between multichannel travel agencies and online travel agencies.

First, we develop an ANOVA for two factors to know, on the one hand, the main effects of both factors over the price and, on the other hand, if the interaction between factors is significant because as we have two factors, we can have a simultaneous influence of the two factors in the price. The results of this analysis for each route appear in tables 1, 2 and 3. 
Table 1. Two-way ANOVA for flight price: route 1

\begin{tabular}{llllll}
\hline & $\begin{array}{l}\text { Sum of } \\
\text { squares type }\end{array}$ & df & Mean square & & F \\
& III & & & & \\
\hline Adjusted model & 79950.580 & 3 & 26650.193 & 5.680 & .001 \\
Intersection & 42966459.463 & 1 & 42966459.463 & 9157.502 & .000 \\
Geographical location & 59606.947 & 1 & 59606.947 & 12.704 & .000 \\
Type of retailer & 16546.527 & 1 & 16546.527 & 3.527 & .061 \\
Location * Retailer & 4720.736 & 1 & 4720.736 & 1.006 & .316 \\
Error & 4147675.752 & 884 & 4691.941 & & \\
\hline Total & 62645989.064 & 888 & & & \\
Adjusted total & 4227626.332 & 887 & & & \\
\hline
\end{tabular}

Source: Own elaboration

Table 2. Two-way ANOVA for flight price: route 2

\begin{tabular}{lllllll}
\hline & $\begin{array}{l}\text { Sum of squares } \\
\text { type III }\end{array}$ & df & Mean square & F & Sig. \\
& 2675259.483 & 3 & 891753.161 & 5.021 & .002 \\
\hline Adjusted model & $1.457 \mathrm{E} 9$ & 1 & $1.457 \mathrm{E} 9$ & 8203.251 & .000 \\
Intersection & 79240.137 & 1 & 79240.137 & .446 & .504 \\
Geographical location & 2305013.795 & 1 & 2305013.795 & 12.978 & .000 \\
Type of retailer & 106555.681 & 1 & 106555.681 & .600 & .439 \\
Location * Retailer & $1.570 \mathrm{E} 8$ & 884 & 177616.010 & & \\
Error & $2.180 \mathrm{E} 9$ & 888 & & & \\
\hline Total & $1.597 \mathrm{E} 8$ & 887 & & & \\
Adjusted total & & & & & \\
\hline
\end{tabular}

Source: Own elaboration 
Table 3. Two-way ANOVA for flight price: route 3

\begin{tabular}{lllllll}
\hline & $\begin{array}{l}\text { Sum of squares } \\
\text { type III }\end{array}$ & df & Mean square & F & Sig. \\
\hline Adjusted model & 3497502.030 & 3 & 1165834.010 & 8.956 & .000 \\
Intersection & $1.193 \mathrm{E} 9$ & 1 & $1.193 \mathrm{E} 9$ & 9165.776 & .000 \\
Geographical location & 33775.772 & 1 & 33775.772 & .259 & .611 \\
Type of retailer & 2911581.146 & 1 & 2911581.146 & 22.367 & .000 \\
Location * Retailer & 304286.782 & 1 & 304286.782 & 2.338 & .127 \\
Error & $1.151 \mathrm{E} 8$ & 884 & 130175.516 & & \\
\hline Total & $1.789 \mathrm{E} 9$ & 888 & & & \\
Adjusted total & $1.186 \mathrm{E} 8$ & 887 & & & \\
\hline
\end{tabular}

Source: Own elaboration

The results in these tables show that average flight prices differ significantly when taking into account the two factors separately but the interaction, that appears in the table as Location*Retailer, is not significant. Therefore, we analyze the individual effects since consider the interactions, when these are not significant in any of the case, complicate the results interpretation. Thus, in the case of route 1 , average prices differ significantly in relation to the geographical location. For the other routes, the type of retailer is the factor with significant differences. Nevertheless, in route 1 the differences between average prices in function of the type of retailer are significant at the $6 \%$ level and, therefore, we include this factor in the subsequent analysis. These results are to be expected as significant differences are only found for the Madrid-Paris route, whereas for the other routes the differences in the average price are not significant.

These results require the development of single-factor ANOVAs that separately examine the factor with significant differences for each route. Furthermore, it should be borne in mind that the factors used only have two values and, therefore, it is not possible to develop a post-hoc analysis. First of all, we identify the statistic that can be used to carry out the analysis of variance for one factor by checking for variance homogeneity. In order to do so, we have used the Levene statistic, the results of which can be observed in Table 4. 
Table 4. Variance homogeneity test

\begin{tabular}{lllllll}
\hline Factor & Route & $\begin{array}{l}\text { Levene } \\
\text { statistic }\end{array}$ & $\mathbf{d f 1}$ & $\mathbf{d f 2}$ & Sig. \\
\hline Geographical location & $\mathbf{1}$ & 80.352 & 1 & 886 & .000 \\
\hline Type of retailer & $\mathbf{1}$ & 4.048 & 1 & 886 & .045 \\
\hline Type of retailer & $\mathbf{2}$ & 18.032 & 1 & 886 & .000 \\
\hline Type of retailer & $\mathbf{3}$ & 22.075 & 1 & 886 & .000 \\
\hline
\end{tabular}

Source: Own elaboration

The results in Table 4 verify that the variances are not homogeneous and, therefore, that we can use the Welch statistic to perform the analysis of variance in all of the cases.

Table 5. Flight price analysis of variance

\begin{tabular}{llllll}
\hline Factor & Route & df1 & df2 & Welch & Sig. \\
\hline Geographical location & $\mathbf{1}$ & 1 & 819.989 & 12.472 & .000 \\
\hline Type of retailer & $\mathbf{1}$ & 1 & 354.110 & 3.205 & .074 \\
\hline Type of retailer & $\mathbf{2}$ & 1 & 529.986 & 18.032 & .000 \\
\hline Type of retailer & $\mathbf{3}$ & 1 & 536.073 & 31.294 & .000 \\
\hline
\end{tabular}

Source: Own elaboration

The results in Table 5 verify the results in Tables 1,2 and 3 since when we analyze the factors separately, the difference in the average price according to the type of retailer for route 1 is significant, but at a significance level of $7.4 \%$. With regards the geographical location, the results for route 1 show significant differences in the averages. For the other routes, there are significant differences in the average price in relation to the type of retailer. After analyzing these results, we calculated the average price for the flights in relation to the different options for these factors. The results are shown in Table 6. 
Table 6. Average prices

\begin{tabular}{|c|c|c|c|c|}
\hline & & $\begin{array}{l}\text { Multichannel } \\
\text { agency }\end{array}$ & $\begin{array}{l}\text { Online } \\
\text { agency }\end{array}$ & 1 Total \\
\hline \multirow{3}{*}{ 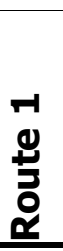 } & Spain & 252.182 & 236.889 & 248.359 \\
\hline & France & 265.779 & 261.135 & 264.618 \\
\hline & Total & 258.981 & 249.012 & 256.489 \\
\hline \multirow{3}{*}{ 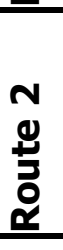 } & Spain & 1561.485 & 1418.527 & 1525.745 \\
\hline & France & 1514.371 & 1422.009 & 1491.281 \\
\hline & Total & 1537.928 & 1420.268 & 1508.513 \\
\hline \multirow{3}{*}{ 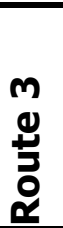 } & Spain & 1433.096 & 1258.108 & 1389.349 \\
\hline & France & 1376.104 & 1286.615 & 1353.732 \\
\hline & Total & 1404.599 & 1272.362 & 1371.540 \\
\hline
\end{tabular}

Source: Own elaboration.

The lowest price for all routes was found via the online travel agencies although, as we have shown in Table 5, the differences in the average prices for routes 2 and 3 are significant only at the 5\% level.

Taking into account the geographical location of the travel agency, the lowest price for route 1 was offered by the Spanish agencies, while the lowest price for the other two routes was offered by the French agencies. These differences, however, are not significant. In addition, the lowest average price for all flights was found via the Spanish online travel agency.

Another important aspect in the analysis of price behaviour is price dispersion; however, there is no consensus in the literature as to the most accurate measurement to use in order to measure the variability. In this paper, we have used the coefficient of variation because this measurement of relative dispersion allows us to better compare the results obtained in function of the different factors considered. Table 7 shows the price dispersion in relation to the geographical location of the travel agencies and the type of retailer. 
Table 7. Price dispersion (variation coefficient)

\begin{tabular}{|c|c|c|c|c|}
\hline & & $\begin{array}{l}\text { Multichannel } \\
\text { agency }\end{array}$ & $\begin{array}{l}\text { I Online } \\
\text { agency }\end{array}$ & Total \\
\hline \multirow{3}{*}{ 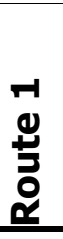 } & Spain & 0.233 & 0.230 & 0.234 \\
\hline & France & 0.281 & 0.332 & 0.294 \\
\hline & Total & 0.260 & 0.294 & 0.269 \\
\hline \multirow{3}{*}{ 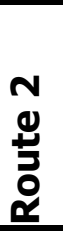 } & Spain & 0.300 & 0.224 & 0.289 \\
\hline & France & 0.284 & 0.229 & 0.273 \\
\hline & Total & 0.293 & 0.226 & 0.281 \\
\hline \multirow{3}{*}{ 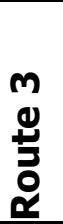 } & Spain & 0.260 & 0.200 & 0.255 \\
\hline & France & 0.290 & 0.228 & 0.278 \\
\hline & Total & 0.275 & 0.214 & 0.267 \\
\hline
\end{tabular}

Source: Own elaboration

The results in terms of price dispersion do not demonstrate a clear behavior pattern. Thus, for routes 1 and 3 the highest price dispersion in relation to the geographical location is found for French travel agencies, while for route 2, Spanish travel agencies show the highest dispersion. In terms of the type of retailer, the results show that for route 1 the highest dispersion is found in online travel agencies' prices, while for the other two routes, this dispersion is highest for the multichannel travel agencies. Surprisingly, however, if we consider the two factors together, it is always the Spanish online travel agencies that show the lowest price dispersion.

\section{CONCLUSIONS}

The emergence of the internet as sales channel, driven by customers attempting to find the lowest prices, has prompted many research papers to analyze the price in the online purchase process. These papers consider different aspects related to prices and work under the assumption that culture is a key factor determining customer behavior. However, there are few papers in the literature that examine the effect of culture from the perspective of the seller.

Consequently, this paper contributes to the literature by analyzing the effect of the geographical location of the travel agencies and the type of retailer on price behavior. In order to analyze the price behavior we included three different routes for six multichannel travel agencies and two online agencies. Specifically, we studied price level and price dispersion using the average price and coefficient of variation respectively. 
The results show that the price level is lower for the online travel agencies and that the lowest average price was found for Spanish online travel agencies. However, in terms of price dispersion there is no clear behavior pattern: the highest or lowest values of the coefficient of variation change according to the different routes. One element to highlight is that the lowest price dispersion was found in Spanish online travel agencies' prices. This indicates, therefore, that this kind of travel agency offers the lowest prices and that these prices do not change notably.

The main limitation of this paper, which at the same time opens up future research lines, is related to the information gathered. First, it would be beneficial to collect information from a travel agency that only sells its products out of its physical premises. These days, however, it is very difficult to find such a travel agency and it would be practically impossible for them to collaborate with us. Second, we could expand the analysis by including information about more routes and travel characteristics. For example, we could examine destinations with different characteristics (tourist/non-tourist), different dates of travel, and so on. Finally, with regards to online travel agencies we have considered only lastminute because it is the most obvious example of a website with different domains in Spain and France, although further research would allow us to find other online travel agencies and thus to collect more information from this kind of travel agency. 


\section{REFERENCES}

- $\quad$ Alderighi, M. (2010). Fare dispersions in airline markets: a quantitative assessment of theoretical explanations. Journal of Air Transport Management 16 (3), 144-150.

- $\quad$ Alegre, J. and Sard, M. (2008) Price dispersion: an empirical analysis in the tour operating industry. Tourism Analysis 14(3), 255- 265.

- $\quad$ Alfaro, J.L.; Andrés, M.E. and Trinquecoste, J.F. (2015). The effect of the economic crisis on the behaviour of airline ticket prices. A case-study analysis of the New York-Madrid route. Journal of Air Transport Management 47, 48-53.

- $\quad$ Armstrong, R.W.; Mok, C.; Go, F.M. and Chan, A. (1997) The importance of cross-cultural expectations in the measurement of service quality perceptions in the hotel industry. International Journal of Hospitality Management 16(2), 181-190.

- Ancarani, F. and Shankar, V. (2009) Price levels and price dispersion within and across multiple retailer types: further evidence and extension. Journal of the Academy of Marketing Science 32(2) 176-187.

- $\quad$ Andrés, M.E.; Gómez, M.A. and Mondéjar, J.A. (2014) Flight prices on the internet price differences and price variability between intermediaries. Journal of Transport Economic and Policy $48(1), 1-13$.

- $\quad$ Bailey, J. (1998) Intermediation and Electronic Markets: Aggregation and Pricing in Internet Commerce. Doctoral dissertation, Technology, Management and Policy, Massachusetts Institute of Technology, Cambridge, MA., at: http://hdl.handle.net/1721.1/9835.

- $\quad$ Bakos, Y.; Lucas, H.C.; Oh, W.; Simon, G.; Viswanathan, S. and Weber, B.W. (2005). The Impact of E-Commerce on competition in the Retail Brokerage Industry. Information System Research 16(4), 352-371.

- Brown, J.R. and Goolsbee, A. (2002) Does the Internet Make Markets More Competitive? Evidence from the Life Insurance Industry. Journal of Political Economy 110(3), 481-507.

- $\quad$ Brynjolfsson, E. and Smith, M. (2000) Frictionless Commerce? A Comparison of Internet and Conventional Retailers. Management Science 46(4), 563-585.

- Chen, J.S.; and Gursoy, D. (2000) Cross-cultural comparison of the information sources used by first-time and repeat travelers and its marketing implications. International Journal of Hospitality Management 19(2), 191-203.

- Clark, R.; and Vincent, N. (2012) Capacity-contingent pricing and competition in the airline industry. Journal of Air Transport Management 24, 7-11. 
- $\quad$ Clay, K.; Krishnan, R.; Wolff, E. and Fernandes, D. (2002) Retail Strategies on the Web: Price and Non-price Competition in the Online Book Industry. Journal of Industrial Economics 50(3), 351-367.

- $\quad$ Clay, K. and Tay, C.H. (2001, May). Cross-Country Price Differentials in the Online Textbook Market. Working Paper, Pittsburgh, PA: Carnegie Mellon University, at: http://citeseerx.ist.psu.edu/viewdoc/summary?doi=10.1.1.25.3595.

- Clemons, E.; Hann, I. and Hitt, L.M. (2002) Price Dispersion and Differentiation in Online Travel: An Empirical Investigation. Management Science 48(4), 534-549.

- $\quad$ Erevelles, S.; Rolland, E. and Srinivasan, S. (2001) Are Prices Really Lower on the Internet?: An Analysis of the Vitamin Industry. Working Paper. Riverside: University of California.

- $\quad$ Friesen, M. (2005). Perceived price fairness in the airline industry. Sib Kongress. Available at: http://www.garsonline.de/Downloads/050609/Friesen_paper.pdf.

- Gaggero, A.A. and Piga, C.A. (2010) Airline competition in the British Isles. Transportation Research Part E: Logistics and Transportation Review 46 (2), 270-279.

- Gaggero, A.A. and Piga, C.A. (2011) An airline market power and intertemporal price

- $\quad$ dispersion. The Journal of Industrial Economics, 59 (4), 552-577.

- Gillen, D. and Mantin, B. (2009) Price volatility in the airline markets. Transportation Research Part E 45(5), 693-709.

- Gursoy, D. and Umbreit, T. W. (2004) Tourist information search behavior: Cross-cultural comparison of European union member states. International Journal of Hospitality Management 23(1), 55-70.

- $\quad$ Hernandez, M. and Wiggins, S. (2014) Nonlinear pricing strategies and market concentration in the airline industry. Economic Inquiry, 52(2), 539-561.

- Huang J.H.; Huang C.T. and Wu S. (1996) National character and response to unsatisfactory hotel service. International Journal of Hospitality Management 15(3), 229-243.

- Huang, J.H.; Chang, C.T. and Chen, C. (2005) Perceived Fairness of pricing on the Internet. Journal of Economic Psychology 26(1), 343-361.

- Huang, W. and Swaminathan, J.M. (2009) Introduction of a second channel: implications for pricing and profits. European Journal of Operational Research, 194, 258-279.

- Jarvenpaa S.L.; Tractinsky, N. and Saarinen, L. (1999). Consumer trust in an Internet store: A cross-cultural validation. Journal of Computer-Mediated Communication, 5(2). 
- Jordan, E.J.; Norman, W.C. and Vogt, C.A. (2013) A cross-cultural comparison of online travel information search behaviors. Tourism Management Perspectives 6, 15-22.

- Kannan, P.K. and Kopalle, P.K. (2001) Dynamic pricing on the Internet: Importance and implications for Consumer behaviour. International Journal of Electronic Commerce 5(3), 63-83.

- Kozak, M. (2001) Comparative assessment of tourist satisfaction with destinations across two nationalities. Tourism Management, 22, 391-401.

- Kozak, M. and Nield, K. (1998). Importance performance analysis and cultural perspectives in Romanian Black Sea resorts. Anatolia: An International Journal of Tourism and Hospitality Research, 9(2), 99-116.

- Kung, M., Monroe, K.B., and Cox, J.L. (2002) Pricing on the Internet. Journal of Product \& Brand Management 11(5), 274-287.

- $\quad$ Lee, Z. and Gosain, S. (2002) A Longitudinal Price Comparison for Music CDs in Electronics and Brick-and-Mortar Markets: Pricing Strategies in Emergent Electronic Commerce. Journal of Business Strategies 19(1), 55-71.

- $\quad$ Li, M. (2014) «Cross-Cultural Tourist Research: A Meta-Analysis. Journal of Hospitality \& Tourism Research 38(1), 40-77.

- Li, N. and Kirkup, G. (2007) Gender and cultural differences in Internet use: A study of China and the UK. Computers in Education 48(2), 301-317.

- $\quad$ Luk, S.T.K.; De Leon, C.T.; Leong, F-W. and Li, E.L.Y. (1994) Value segmentation of tourists ' expectations of service quality. Journal of Travel and Tourism Marketing 2(4), 23-38.

- $\quad$ McLellan, R.W. and Fousher, K.D. (1983) Negative images of the United States as expressed by tour operators from other countries. Journal of Travel Research 22, 2-5.

- $\quad$ Obermeyer, A.; Evangelinos, C. and Püschel, R. (2013) Price dispersion and competition in European airline markets. Journal of Air Transport Management 26, 31-34.

- Park, C. and Jun, J-K. (2003) A cross-cultural comparison of Internet buying behavior: Effects of Internet usage, perceived risks, and innovativeness. International Marketing Review 20(5), 534-553.

- Ruiz, C.; Sanz, S., Hernández, B. and Brethouwer, M. (2013) Key drivers of consumer purchase of airline tickets: a cross-cultural analysis. Journal of Air Transport Management 27, 1114.

- Mantin, B. and Koo, B. (2009) Dynamic price dispersion in airline markets. Transportation Research Part E: Logistics and Transportation Review 45, 1020-1029. 
- Morton, F.S.; Zettelmeyer, F. and Silva-Risso, J. (2001) Internet Car Retailing. Journal of Industrial Economics 49(4), 501-519.

- Pizam, A. and Jeong, G-H. (1996) Cross-cultural tourist behavior: Perceptions of Korean tour-guides. Tourism Management 17(4), 277-286.

- $\quad$ Pizam, A. and Sussmann, S. (1995) Does nationality a!ect tourism behavior? Annals of Tourism Research 22(4), 901-917.

- Richardson, S.L. and Crompton, J. (1988) Vacation patterns of French and English Canadians. Annals of Tourism Research 15(4), 430-448

- $\quad$ Scholten, P.A. and Smith, A. (2002) Price Dispersion Then and Now: Evidence from Retail and E-Tail Markets. Advances in Microeconomics: Economics of the Internet and e-Commerce 11, $63-88$

- Stylianou, A.C.; Kumar, R.L. and Robbins, S.S. (2005) Pricing on the Internet and in conventional retail channels: a study of over-the-counter pharmaceutical products. International Journal of Electronic Commerce, 10, 135-148.

- Sussmann, S. and Rashcovsky, C. (1997) A cross-cultural analysis of English and French Canadians' vacation travel patterns. International Journal of Hospitality Management 16(2), 191208.

- Yoon, C. (2009) The effects of national culture values on consumer acceptance of ecommerce: online shoppers in China. Information \& Management 46, 294-301.

- Zettelmeyer, F. (2000). Expanding to the Internet: pricing and communication strategies when firms compete on multiple channels. Journal of Marketing Research 37(3), 292-308.

- Zettelmeyer, F.; Morton, F. and Silva-Risso, J. (2006). How the Internet lowers prices: evidence from matched survey and automobile transaction data. American Marketing Association $43,168-181$. 